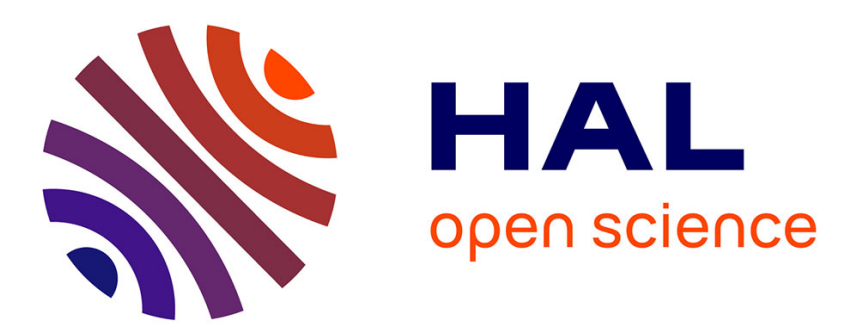

\title{
Structure and optical properties of core-shell bimetallic AgnNin clusters: Comparison with pure silver and nickel clusters
}

\author{
M. Harb, F. Rabilloud, D. Simon
}

\section{- To cite this version:}

M. Harb, F. Rabilloud, D. Simon. Structure and optical properties of core-shell bimetallic AgnNin clusters: Comparison with pure silver and nickel clusters. Journal of Chemical Physics, 2009, 131 (17), pp.174302. 10.1063/1.3257900 . hal-03510472

\section{HAL Id: hal-03510472 \\ https://hal.science/hal-03510472}

Submitted on 13 Jan 2022

HAL is a multi-disciplinary open access archive for the deposit and dissemination of scientific research documents, whether they are published or not. The documents may come from teaching and research institutions in France or abroad, or from public or private research centers.
L'archive ouverte pluridisciplinaire HAL, est destinée au dépôt et à la diffusion de documents scientifiques de niveau recherche, publiés ou non, émanant des établissements d'enseignement et de recherche français ou étrangers, des laboratoires publics ou privés. 


\title{
Structure and optical properties of core-shell bimetallic $\mathrm{Ag}_{n} \mathrm{Ni}_{n}$ clusters: Comparison with pure silver and nickel clusters
}

\author{
M. Harb, F. Rabilloud, ${ }^{\text {a) }}$ and D. Simon \\ Université de Lyon, F-69622 Lyon, France; Université Lyon 1, Villeurbanne; CNRS, UMR 5579, LASIM
}

(Received 29 June 2009; accepted 12 October 2009; published online 2 November 2009)

\begin{abstract}
We present the structural, electronic, and optical properties of bimetallic $\mathrm{Ag}_{n} \mathrm{Ni}_{n}(n \leq 7)$ clusters investigated in the framework of the density functional theory (DFT) (DFT and time-dependent DFT). The structure of $\mathrm{Ag}_{n} \mathrm{Ni}_{n}$ clusters is found to be governed essentially by the formation of a Ni-core surrounded by silver atoms. The cohesive energies and the ionization potentials are calculated. The UV-visible absorption spectra of bimetallic clusters are compared to those of pure silver and nickel clusters. An interpretation of spectroscopic patterns in terms of contribution from $s$ - and $d$-type excitations is also given. In particular the $d$ electrons of nickel atoms are found to play a crucial role in the optical transitions in Ni-rich systems. (C) 2009 American Institute of Physics.

[doi:10.1063/1.3257900]
\end{abstract}

\section{INTRODUCTION}

The physics of nanoscaled systems was strongly developed in the past 20 years, thanks to progresses in both experimental and theoretical approaches, and application outlooks appear to be more and more promising. Properties of nanoparticles can be tailored not only by modifying the size but also by mixing several elements together. In particular, the bimetallic nanoclusters constitute rich systems with peculiar and unique structural, ${ }^{1-12}$ electronic, ${ }^{1-3,9-11}$ optical, $^{13-17}$ and magnetic ${ }^{18-20}$ properties. The wealth of these systems can lead to a large variety of applications; there is a technological interest in catalysis ${ }^{21,22}$ and also in the developing of new nanodevices for electronics. ${ }^{23}$

At the nanometric scale, the atomic arrangement in a bimetallic system is found either as random alloy or as segregated structures such as core/shell systems. This depends mainly on the nature of both metals components but also on the method of preparation. ${ }^{17,24}$ For the mixed silver-nickel clusters which are concerned in the present work, core/shell configurations with the core nickel atoms surrounded by surface silver atoms are expected. This segregation can be explained by several factors. First, steric effects are present since the Wigner-Seitz radius for $\mathrm{Ag}$ is larger than that for $\mathrm{Ni}$ (3.02 and 2.6 a.u., respectively ${ }^{17}$ ). Second, the $\mathrm{Ni}-\mathrm{Ni}$ bonds are stronger than the $\mathrm{Ag}-\mathrm{Ni}$ and $\mathrm{Ag}-\mathrm{Ag}$ ones. Third, the surface energy of silver is almost twice smaller than the nickel one. Lastly, the phase diagrams of $\mathrm{Ag}-\mathrm{Ni}$ systems show that silver and nickel are immiscible even at high temperature. ${ }^{25,26}$ Experimentally, the core-shell structure was confirmed by low energy ion spectroscopy measurements showing that the clusters surface is essentially composed of silver atoms. ${ }^{17}$ However, very recently, Zhang et al. ${ }^{24}$ succeeded to synthesize stable $\mathrm{Ag}-\mathrm{Ni}$ alloy nanoparticles by radiolytic approaches, although the alloy phase is not ther-

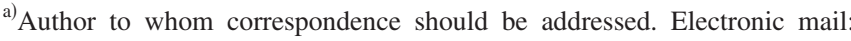
franck.rabilloud@lasim.univ-lyon1.fr. Telephone: 334724329 31. Fax: 33472431507 .
}

modynamically favorable. From a theoretical point of view, the research of most stable structures of bimetallic clusters remains a challenge due to the huge amount of combinatorial possibilities of isomers. If one metal is magnetic, the study becomes more complicated because several spin states must be investigated. Ferrando and co-workers ${ }^{4-8,12}$ studied the structures of bimetallic silver-nickel clusters of different sizes going from a few dozens to a few hundreds atoms, thanks to a global optimization with the use of a semiempirical potential. For the smallest clusters, they performed a local reoptimization in the framework of the density functional theory (DFT) by taking into account the spin multiplicity. The lowest-energy isomers were found to be polyicosahedrons of core-shell type with core nickel and surface silver atoms. In a previous work, ${ }^{27}$ we found in a DFT study on small $\mathrm{Ag}_{n} \mathrm{Ni}_{p}(n+p \leq 6)$ clusters that the nickel atoms are brought together, yielding a maximum of $\mathrm{Ni}-\mathrm{Ni}$ bonds, while the silver atoms are located around a Ni-core with a maximum of Ag-Ni bonds. Recently, Calvo et al. ${ }^{25}$ with Monte Carlo simulations showed that the Ni-core/Ag-shell configuration is thermodynamically stable up to $810 \mathrm{~K}$.

The optical properties of metallic clusters are very attractive due to their importance in both basic and applied researches. In particular several experimental and theoretical studies have been carried out for silver nanoclusters. ${ }^{28-34}$ For small $\mathrm{Ag}_{n}$ clusters $(n \leq 8)$, the absorption spectra are characterized by a strong response in the $3-5 \mathrm{eV}$ range with several narrow or broad peaks associated mainly with $s$-electrons, while for $n \geq 12$ they are characterized by the emergence of a dominant and relatively broad peak between 3.2 and $3.8 \mathrm{eV}$ due to transitions associated to $d$-electrons. ${ }^{34}$ The study of the optical properties is more complicated for bimetallic clusters since the properties should depend not only on the size but also on the chemical composition and the atomic arrangement. Due to their unique structural and electronic properties, ${ }^{4-8,13-17,35}$ the small bimetallic noble metal-nickel clusters seem to be very interesting to carry out the optical spectroscopy and to examine the influence of nickel on the 
absorption spectra. However very few investigations bore on silver-nickel systems. In a recent study of the optical properties ${ }^{17}$ it was shown that the absorption spectra of large $\mathrm{Ag}-\mathrm{Ni}$ bimetallic (about 2-5 nm of size) clusters are intermediate between those of pure silver and pure nickel clusters, with a surface plasmon resonance enlarged and blueshifted compared to pure silver clusters. In previous works, ${ }^{35}$ we have investigated the optical properties of small bimetallic $\mathrm{Ag}_{n} \mathrm{Ni}_{p}(n+p \leq 8)$ clusters in the framework of the timedependent DFT (TDDFT) and shown that the UV-visible absorption spectra are broadened and blueshifted with the increasing nickel atomic number compared to the pure silver $\mathrm{Ag}_{n}$ clusters, consistent with the experimental measurements for the large $\mathrm{Ag}-\mathrm{Ni}$ clusters.

In this paper, we investigate the preferential spatial distribution of nickel atoms in $\mathrm{Ag}_{n} \mathrm{Ni}_{n}$ clusters, with $n \leq 7$, in order to highlight an aggregation or a random distribution. Each structure will be characterized by its electronic and optical properties. Geometrical properties are investigated in the framework of the DFT while the UV-visible absorption spectra are calculated in the TDDFT approach. The evolution of the optical properties with the size and the spatial positions of $\mathrm{Ni}$ atoms are analyzed. The spectra will be compared to those of pure silver or nickel clusters. An interpretation of spectroscopic patterns in terms of contribution from $s$ - and $d$-types excitations will also be given.

\section{CALCULATIONS}

The cluster geometries were optimized in the framework of the DFT implemented in the GAUSSIAN03 package. ${ }^{36}$ The exchange and correlation functional of second generation of type GGA (generalized gradient approximation) called BP86 that includes the exchange functional of Becke ${ }^{37}$ and the correlation one of Perdew ${ }^{38}$ was used. Following previous studies $^{31,39-41}$ on the structural, electronic, and optical properties of the silver clusters or binary clusters including $\mathrm{Ag}$ atoms which showed that explicit treatment of the $4 s, 4 p$, and $4 d$ electrons of silver atoms as active valence electrons are necessary to describe correctly the electronic structure, both silver and nickel atoms were represented through LANL2DZ relativistic effective core potential ${ }^{42}$ as $\left[\mathrm{Ag}^{19+}\right]$ and $\left[\mathrm{Ni}^{18+}\right]$, respectively. The associated Gaussian basis sets were $(8 s 6 p 4 d)$ contracted in $[3 s 3 p 2 d]$ on each silver atom, and $(8 s 5 p 5 d)$ contracted in $[3 s 3 p 2 d]$ on each nickel atom.

In the optimization process of $\mathrm{Ag}_{n} \mathrm{Ni}_{n}$ cluster geometries, a great number of structures were tested for each size. We have initiated the geometry optimization process of $\mathrm{Ag}_{n} \mathrm{Ni}_{n}$ clusters starting from most stable structures known for $\mathrm{Ag}_{2 n}$ clusters, ${ }^{34}$ in which half silver atoms were replaced by $\mathrm{Ni}$ ones in considering all the possible spatial distribution. We have also tested three-dimensional structures such as those of $\mathrm{Ni}_{2 n}$ (Refs. 27, 43, and 44) or $\mathrm{Ni}_{n}$ covered by silver atoms. Finally, we have tried to construct $\mathrm{Ag}_{n} \mathrm{Ni}_{n}$ clusters starting from structures obtained for $\mathrm{Ag}_{n-1} \mathrm{Ni}_{n-1}$ isomers by adding one silver atom and one nickel atom on the different possible sites. Harmonic frequencies analysis was performed to guarantee that the optimized structures are local minima. Of course, the explicit treatment of all the electrons in a

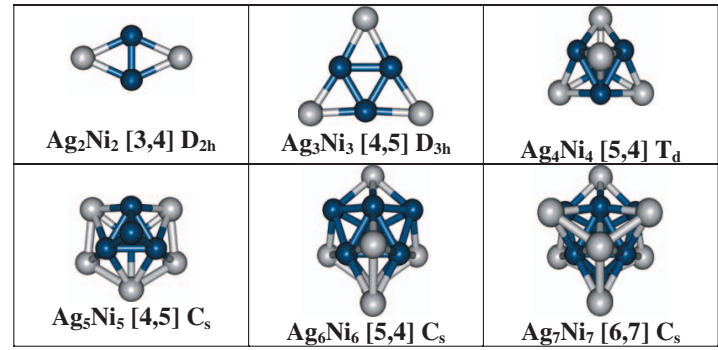

FIG. 1. Lowest-energy isomers for $\mathrm{Ag}_{n} \mathrm{Ni}_{n}(n=2-7)$ clusters. The spin multiplicities for the neutral (first entry) and the cationic (second entry) systems are given in square brackets. Spatial symmetries are also given. The silver atoms are shown in light gray while the nickel atoms are in dark (blue online) color.

cluster having a large number of atoms constitutes a demanding computational task and the search for the lowest-energy isomer cannot include a global optimization procedure of the potential energy surface. So we cannot be sure that a more stable cluster than those found in our calculations does not exist. As nickel is a magnetic metal, several spin multiplicities for each structure were tested.

The calculation of the optical properties (excitation energies, oscillator strengths, and transition dipole moments) has been carried out in the framework of the TDDFT implemented in Q-CHEM.3.0 (Ref. 45) with the time-dependent Kohn-Sham formalism and related techniques by employing LANL2DZ relativistic effective core potentials with the BP86 functional. The choice of BP86 functional for absorption spectra calculations is justified below (absorption spectra section) as a compromise between reliable results and a reasonable computation cost. Pre- and postprocessing operations were performed with the graphical interface GABEDIT. ${ }^{46}$

\section{RESULTS AND DISCUSSION}

\section{A. Optimized structures and energetics}

The lowest-energy isomers of $\mathrm{Ag}_{n} \mathrm{Ni}_{n}$ are shown in Fig. 1, together with the spin multiplicity and the spatial symmetry. For $n=2,3$, and 4 , the structures are found very similar to those of pure $\mathrm{Ag}_{2 n}$ clusters, ${ }^{27,34}$ that is, a rhombus for $\mathrm{Ag}_{2} \mathrm{Ni}_{2}$, a triangle for $\mathrm{Ag}_{3} \mathrm{Ni}_{3}$, and a tetrahedron for $\mathrm{Ag}_{4} \mathrm{Ni}_{4}$. For each size, nickel atoms are brought together, yielding a maximum of $\mathrm{Ni}-\mathrm{Ni}$ bonds, and the silver atoms are located around a $\mathrm{Ni}$-core with a maximum of $\mathrm{Ag}-\mathrm{Ni}$ bonds. The structures of $\mathrm{Ag}_{5} \mathrm{Ni}_{5}, \mathrm{Ag}_{6} \mathrm{Ni}_{6}$, and $\mathrm{Ag}_{7} \mathrm{Ni}_{7}$ are very compact with the localization of one $\mathrm{Ni}$ atom at the center of the structure. The latter forms a connection with all the other $\mathrm{Ni}$ atoms, while silver atoms are distributed on the surface. For $n \geq 5$, each structure can be seen as a piece of a 13-atom icosahedron with a particular $\mathrm{Ni}$ atom having a great number of neighbors and seeming to be the center of the full icosahedron.

The structure of $\mathrm{Ag}_{n} \mathrm{Ni}_{n}$ clusters is governed essentially by the formation of a $\mathrm{Ni}$-core surrounded by silver atoms. For small $n$ values $(n \leq 5), \mathrm{Ag}_{n} \mathrm{Ni}_{n}$ is formed by the lowestenergy isomer of $\mathrm{Ni}_{n}$ (a triangle, a compact tetrahedron, and 


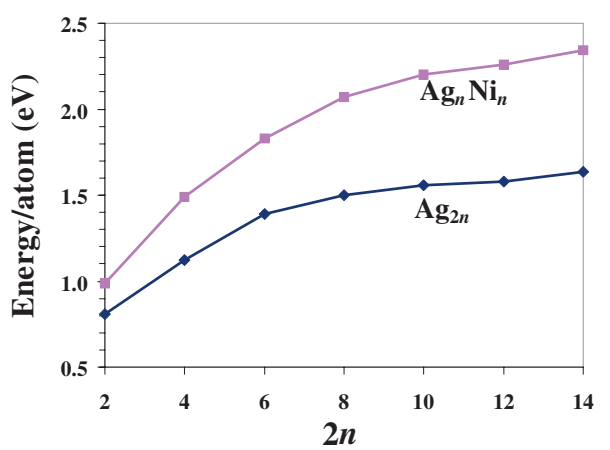

FIG. 2. Cohesive energies of $\mathrm{Ag}_{n} \mathrm{Ni}_{n}$ and $\mathrm{Ag}_{2 n}$ clusters $(n=2-7)$.

a triangular bipyramid for $n=3,4$, and 5 , respectively ${ }^{27,43,44}$ ) on which silver atoms are adsorbed. However, for larger size the presence of silver atoms leads to a deformation of the $\mathrm{Ni}_{n}$ cluster and the $\mathrm{Ni}$-core is no longer the lowest-energy isomer of $\mathrm{Ni}_{n}$. Hence, although $\mathrm{Ni}_{6}$ is a square bipyramid, ${ }^{27}$ the Ni-core in $\mathrm{Ag}_{6} \mathrm{Ni}_{6}$ is an opened pentagonal bipyramid.

Our results show that starting from $n=5$, the structure of $\mathrm{Ag}_{n} \mathrm{Ni}_{n}$ can be built from that of $\mathrm{Ag}_{n-1} \mathrm{Ni}_{n-1}$ by adding two silver atoms on the surface and then by substituting some silver atoms by nickel ones. For example, the structure of $\mathrm{Ag}_{7} \mathrm{Ni}_{7}$ is obtained from that of $\mathrm{Ag}_{6} \mathrm{Ni}_{6}$ by adding two silver atoms in surface to complete two pentagonal bipyramids, and simultaneously by substituting a silver atom by a $\mathrm{Ni}$ one. Similarly, the structure of $\mathrm{Ag}_{6} \mathrm{Ni}_{6}$ can be built from that of $\mathrm{Ag}_{5} \mathrm{Ni}_{5}$ by adding two silver atoms in surface and then by substituting simultaneously two silver atoms by nickel, and a nickel by a silver atom.

Several spin multiplicities were tested for each structure. For example, for $\mathrm{Ag}_{4} \mathrm{Ni}_{4}$ the lowest-energy isomer with the triplet spin multiplicity is found $0.23 \mathrm{eV}$ above the quintet, and for $\mathrm{Ag}_{5} \mathrm{Ni}_{5}$ the lowest-energy isomer with the sextet spin multiplicity is found $0.32 \mathrm{eV}$ above the quartet. The spin multiplicity of the lowest-energy isomers, given in Fig. 1, is found to increase with the size $n$.

The present calculations, which are the first to investigate the geometry of these relatively large clusters using a theoretical approach completely based on DFT and taking into account the magnetic properties, confirm the segregation and the core/shell character of nickel-silver structures, already predicted in our previous DFT study on very small $(n \leq 3)$ clusters $^{27}$ and by semiempirical approaches for larger clusters. ${ }^{4,5,7}$ The present core/shell structures are consistent with low energy ion spectroscopy measurements on $\mathrm{Ag} / \mathrm{Ni}$ nanoparticles of few nanometers which shown that the cluster surface is essentially composed of silver. ${ }^{17}$

The cohesive energies defined as $\mathrm{E}_{\mathrm{c}}=-\left[\mathrm{E}\left(\mathrm{Ag}_{n} \mathrm{Ni}_{n}\right)\right.$ $-n \mathrm{E}(\mathrm{Ag})-n \mathrm{E}(\mathrm{Ni})] /(2 n)$ are plotted in Fig. 2. The calculations yield a monotonic increase with the size $n$. For comparison, we have included in Fig. 2 the cohesive energies for pure $\mathrm{Ag}_{2 n}$ clusters. The gap between $\mathrm{E}_{\mathrm{c}}\left(\mathrm{Ag}_{n} \mathrm{Ni}_{n}\right)$ and $\mathrm{E}_{\mathrm{c}}\left(\mathrm{Ag}_{2 n}\right)$ increases with the size $n$ from $0.2 \mathrm{eV}$ for $n=2$ to $0.7 \mathrm{eV}$ for $n=7$. This means that substituting $n$ silver by $n$ nickel atoms correspond to a higher cohesive energy as the size $n$ increases because of the growth of the number of

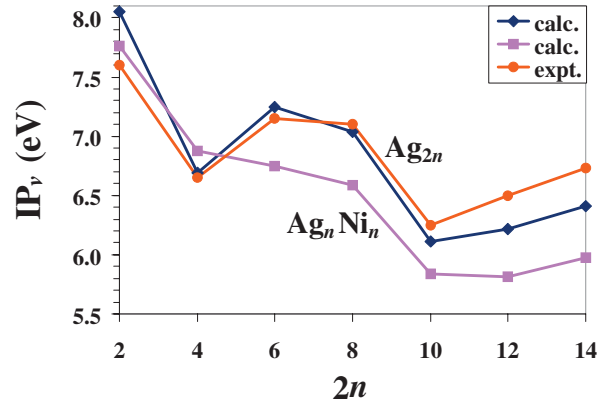

FIG. 3. Calculated vertical ionization potential for $\mathrm{Ag}_{n} \mathrm{Ni}_{n}$ and $\mathrm{Ag}_{2 n}$ clusters $(n=2-7)$. Experimental data for $\mathrm{Ag}_{2 n}$ are taken from Ref. 47.

$\mathrm{Ni}-\mathrm{Ni}$ instead of $\mathrm{Ag}-\mathrm{Ag}$ bonds. This is in good agreement with the fact that it is the lowest-energy isomer which maximizes the number of $\mathrm{Ni}-\mathrm{Ni}$ bonds.

Vertical ionization potential $\left(\mathrm{IP}_{\mathrm{v}}\right)$ was also calculated for each $\mathrm{Ag}_{n} \mathrm{Ni}_{n}$ cluster. The spin multiplicities of the cations are given in Fig. 1. The results are shown in Fig. 3 together with those of $\mathrm{Ag}_{2 n}$ for comparisons. Note that our calculated values for $\mathrm{Ag}_{2 n}$ are in very good agreement with the experimental data. ${ }^{47}$ For $\mathrm{Ag}_{n} \mathrm{Ni}_{n}$ clusters the $\mathrm{IP}_{\mathrm{v}}$ behavior is rather close to that of $\mathrm{Ag}_{2 n}$ with, however, a gap of about $0.4 \mathrm{eV}$ for $n \geq 3$. The gap comes from a change in the composition of the highest occupied molecular orbital (HOMO) in neutral clusters. Indeed, while the HOMO is essentially composed of $s$-type orbitals of silver atoms for $n \leq 2$, a participation of $d$-type orbitals of Ni appears for $n \geq 3$.

\section{B. Absorption spectra \\ 1. Introduction}

In this part, we study the evolution of the UV-visible absorption spectra with the $\mathrm{Ag} / \mathrm{Ni}$ composition. First, we compare the spectra of $\mathrm{Ag}_{n} \mathrm{Ni}_{n}$ clusters to those of $\mathrm{Ag}_{2 n}$ and $\mathrm{Ni}_{2 n}$. The geometrical structures are fixed to those of $\mathrm{Ag}_{2 n}$, i.e., the structures of $\mathrm{Ag}_{n} \mathrm{Ni}_{n}$ and $\mathrm{Ni}_{2 n}$ clusters are obtained by local optimizations starting from the structure of the lowest-energy isomer of $\mathrm{Ag}_{2 n}$ given in Ref. 34 after substitutions of some silver atoms by the nickel ones. For $\mathrm{Ag}_{n} \mathrm{Ni}_{n}$ clusters, several configurations keeping a Ni-core have been tested to find the most stable structure. Several spin multiplicities have been tested for each isomer.

Following previous studies on metallic and bimetallic clusters, ${ }^{34,35,48}$ we have chosen in the present study to use the GGA functional BP86 to optimize the geometries and to calculate the optical spectra. In particular, our recent BP86 calculations of the absorption spectra of silver clusters compare very well with the experimental spectra of clusters isolated in an argon matrix. ${ }^{34}$ However, the BP86 functional is known to give sometimes too small transition energies. ${ }^{49,50}$ To check the reliability of BP86 in the present study, we have compared, in the case of one mixed cluster and one pure silver or nickel cluster, the BP86 spectra with those calculated with two more commonly used functionals: the GGA PBE (Ref. 51) and the hybrid B3LYP. ${ }^{52,53}$ Spectra of $\mathrm{Ag}_{8}, \mathrm{Ag}_{4} \mathrm{Ni}_{4}$, and $\mathrm{Ni}_{8}$ calculated with the three functional are presented in Fig. 4. The spectra, calculated up to $5.5 \mathrm{eV}$, give the oscillator strength as a function of the excitation energy together with a 

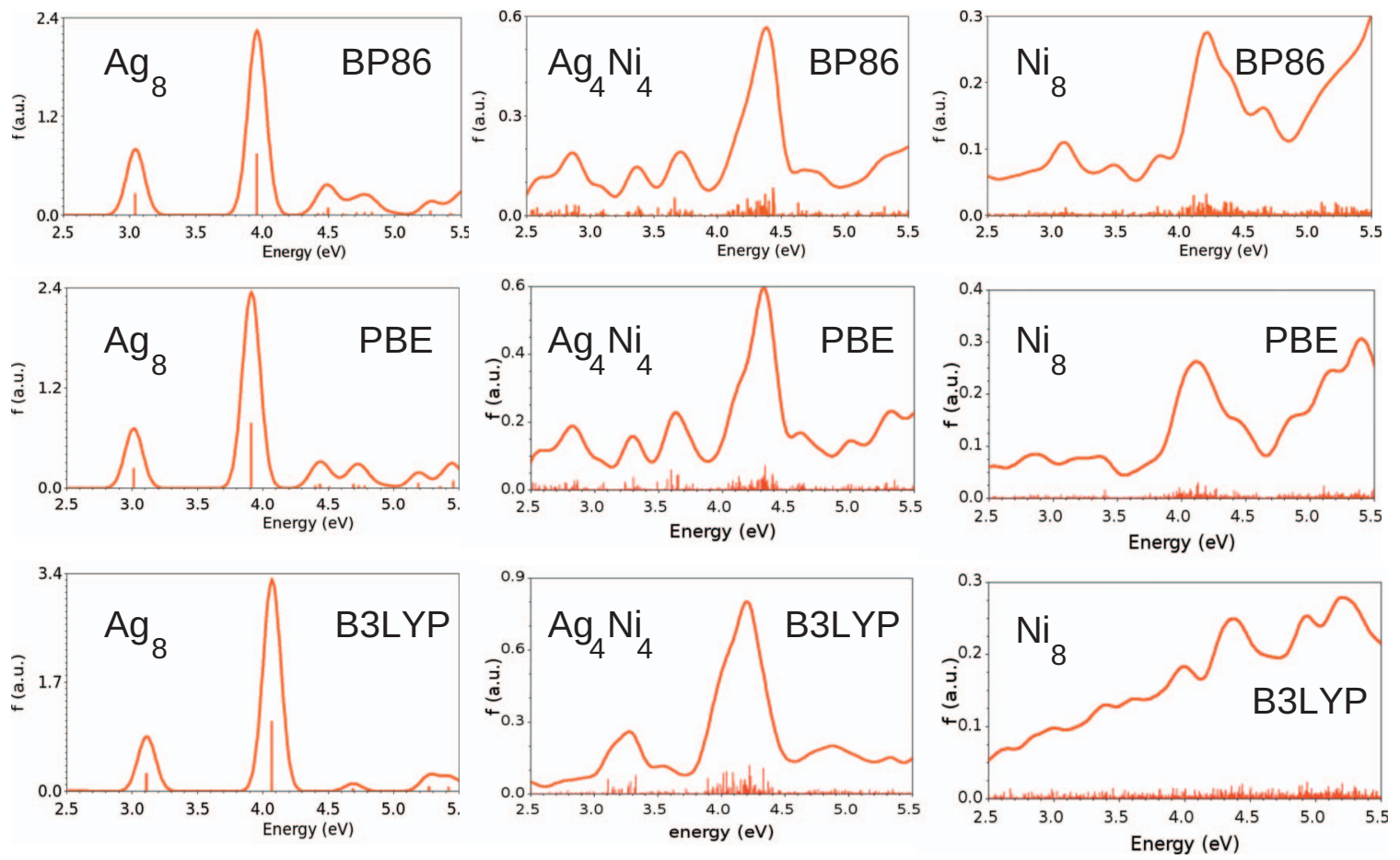

FIG. 4. Absorption spectra of $\mathrm{Ag}_{8}, \mathrm{Ag}_{4} \mathrm{Ni}_{4}$, and $\mathrm{Ni}_{8}$ clusters calculated using BP86, PBE, and B3LYP, respectively.

curve obtained by a Gaussian broadening (with a full width at half maximum of $0.08 \mathrm{eV}$ ). The PBE spectra are found to be nearly identical to those of BP86 for both pure metallic and mixed clusters. The positions of the main peaks are identical and the evolution of the spectra with the increasing nickel atomic number, i.e., a broadening and a blueshift of the optical response with a dispersion of the oscillator strengths on the states in the high energy region, is very similar. The B3LYP spectra are also nearly similar to those of BP86 and PBE. For $\mathrm{Ag}_{8}$, the spectrum presents two narrow peaks. The main peak with B3LYP is slightly blueshifted as compared to that of BP86, the B3LYP, and BP86 values being 4.07 and $3.96 \mathrm{eV}$, respectively. Let us note that the experimental value is $3.90 \mathrm{eV}$, in better agreement with the BP86 value. ${ }^{34}$ For $\mathrm{Ag}_{4} \mathrm{Ni}_{4}$, the main band centered at $4.2 \mathrm{eV}$ is slightly broadened and redshifted with respect to those of BP86 and PBE spectra. At low energy, the B3LYP spectrum shows one low-intensity band centered at $3.25 \mathrm{eV}$ while those of BP86 and PBE present three bands at 2.85, 3.35, and $3.70 \mathrm{eV}$. Finally, the spectrum of $\mathrm{Ni}_{8}$ shows a very strong dispersion of the oscillator strengths on the states in the high energy region, leading to a very large band without any dominant peaks. It is a similar result to those obtained with BP86 and PBE, even if in the case of these two functionals the hollow around $4.7 \mathrm{eV}$ is more marked. Therefore, the spectra calculated with B3LYP appear to be nearly similar to those calculated using BP86 and PBE for the three clusters. So, the hybrid functional does not give prominent features. In the only case for which experimental data are available, i.e., $\mathrm{Ag}_{8}$, the position of the main peak is better described by BP86 than by B3LYP. The evolution of the spectra with the increasing nickel atomic number, from narrow peaks for pure silver clusters to a broadening and a blueshift of the optical response with a dispersion of the oscillator strengths on the states in the high energy region for pure nickel clusters, is very similar with the three functionals. Then, we have chosen to use the BP86 functional as the best compromise between the reliability of results and the cost of computation.

\section{Silver-nickel binary clusters versus pure silver/nickel clusters}

Figure 5 gives the spectra of mixed silver-nickel clusters compared to those of pure silver or nickel. The spectra of pure silver clusters are characterized by a strong optical response in the 3-4 eV range with one or two dominant peaks. In contrast, the spectra of nickel clusters show very lowintensity peaks well scattered on all the range of energy. The dispersion of the oscillator strengths in the high energy region leads to a blueshift compared to the spectra of silver clusters.

The spectra of small $\mathrm{Ag}_{n} \mathrm{Ni}_{n}$ clusters, i.e., $n \leq 3$, are similar to those of $\mathrm{Ag}_{2 n}$ with a dominant peak around $3 \mathrm{eV}$ while those of larger cluster $(n \geq 5)$ are nearly identical to those of $\mathrm{Ni}_{2 n}$ with a very broad band. For $n=2$, the spectrum of $\mathrm{Ag}_{2} \mathrm{Ni}_{2}$ shows a narrow dominant peak at $2.91 \mathrm{eV}$ and several broader bands between 3.8 and $5.5 \mathrm{eV}$, similar to that of $\mathrm{Ag}_{4}$ which presents a dominant peak at $3.0 \mathrm{eV}$ accompanied by two other peaks at higher energies but smaller intensities. It is very different from the spectrum of $\mathrm{Ni}_{4}$ which presents no dominant peak around $3 \mathrm{eV}$ but some broad bands in the high energy region. An analysis of the transitions shows that the main peak at $2.91 \mathrm{eV}$ for $\mathrm{Ag}_{2} \mathrm{Ni}_{2}$ is associated to local excitations with an electron transfer located on each atom, i.e., each atom contributes both to excited and ground states, similar to the case of small $\mathrm{Ag}_{n}$ clusters. ${ }^{35,41}$ The transitions in the high energy region are due to excitations from inner $d$ orbitals of both silver and nickel 

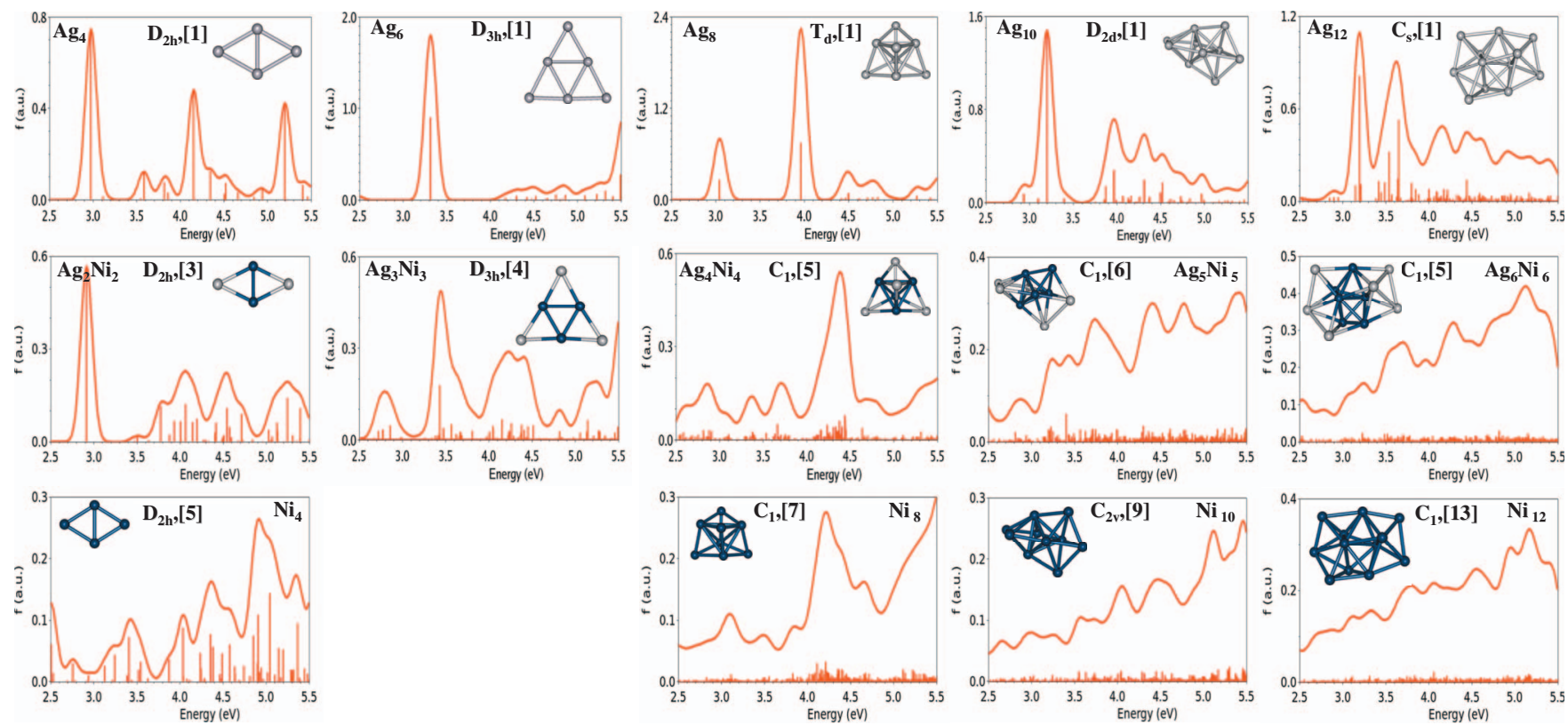

FIG. 5. Absorption spectra of $\mathrm{Ag}_{n} \mathrm{Ni}_{n}, \mathrm{Ag}_{2 n}$, and $\mathrm{Ni}_{2 n}$ clusters $(n=2-6)$. Structures, spin multiplicities, and spatial symmetries are shown.

atoms to an outer region distributed on wide areas involving all atoms with a $s+p$ character. The spectrum of $\mathrm{Ag}_{3} \mathrm{Ni}_{3}$ is dominated by a narrow peak at $3.4 \mathrm{eV}$, blueshifted by $0.1 \mathrm{eV}$ with respect to the peak of $\mathrm{Ag}_{6}$, and two bands centered at 2.75 and $4.3 \mathrm{eV}$. The main peak at $3.4 \mathrm{eV}$ is associated to transitions from $d$ orbitals of nickel and a few contributions of silver atoms to an outer area surrounding the cluster. The excitations at higher energies are due to transitions from $d$ orbitals of both nickel and silver atoms to outer region with an $s+p$ character. The spectrum of $\mathrm{Ni}_{6}$ was not calculated because the triangular structure considered here for this size is not a local minimum. For $n=4$, the spectrum of $\mathrm{Ag}_{4} \mathrm{Ni}_{4}$ seems to be intermediate between those of $\mathrm{Ag}_{8}$ and $\mathrm{Ni}_{8}$, with a dominant band between 4 and $4.5 \mathrm{eV}$ surrounded by several bands at lower intensities. The spectral density is highly increased compared to the case of $\mathrm{Ag}_{8}$ because of the presence of nickel atoms. The main band centered at $4.4 \mathrm{eV}$ for $\mathrm{Ag}_{4} \mathrm{Ni}_{4}$ is broadened and blueshifted as compared to that of $\mathrm{Ag}_{8}$. This broadening cannot be explained uniquely by the breaking of the cluster symmetry but is due to the presence of nickel atoms. For $n \geq 5$, the shape of the spectra of $\mathrm{Ag}_{n} \mathrm{Ni}_{n}$ changes and becomes similar to that of pure nickel clusters with a strong dispersion of the oscillator strengths on all the range of energy without any dominant peak. Besides, the spectral density for $\mathrm{Ag}_{n} \mathrm{Ni}_{n}$ increases with the increasing energy similar to that of $\mathrm{Ni}_{2 n}$ and so the electrons of nickel atoms are expected to play a crucial role in the excitations.

The geometrical structures of $\mathrm{Ag}_{n} \mathrm{Ni}_{n}$ clusters considered above are the lowest-energy isomers for $n=2,3$, and 4, but not for $n=5$ and 6 . Both lowest-energy isomers for $n=5$ and 6, shown in Fig. 1, have a $\mathrm{C}_{\mathrm{s}}$ symmetry, while the structures of Fig. 5 have a $\mathrm{C}_{1}$ symmetry. The Ni cores are similar in both cases but the positions of silver atoms on surface are changed. In Fig. 6, we show the absorption spectra for the $\mathrm{C}_{s}$ isomers of $\mathrm{Ag}_{5} \mathrm{Ni}_{5}$ and $\mathrm{Ag}_{6} \mathrm{Ni}_{6}$ clusters. They are very simi- lar to those of the $\mathrm{C}_{1}$ structures. Hence, the optical spectra are very few dependent on the position of silver atoms in surface.

Finally, the evolution of the spectra of $A g_{n} \mathrm{Ni}_{n}$ with the size $n$ clearly shows a broadening and a blueshift of the optical response with a dispersion of the oscillator strengths on the states in the high energy region. For $\mathrm{Ag}_{2} \mathrm{Ni}_{2}$, a narrow peak is found at $2.91 \mathrm{eV}$, while for $\mathrm{Ag}_{3} \mathrm{Ni}_{3}$, the dominant peak is at $3.4 \mathrm{eV}$, and for $\mathrm{Ag}_{4} \mathrm{Ni}_{4}$ the main peak is found to be broadened and blueshifted to $4.4 \mathrm{eV}$. For $n \geq 5$, there is no longer dominant peak due to the strong dispersion on all states and particularly on states at highest energies.

Our present results on small particles are in very good adequacy with recent experimental ones on large nanoparticles $(\sim 2-5 \mathrm{~nm}$ in size $)$ embedded in an alumina matrix. ${ }^{17}$ Indeed, Gaudry et al. observed a broadening, damping, and
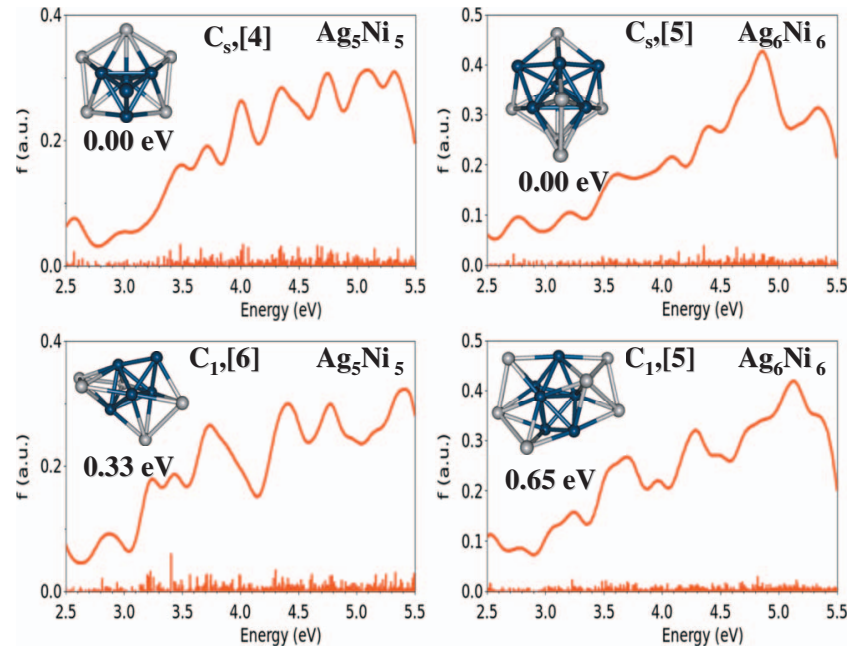

FIG. 6. Absorption spectra of $\mathrm{Ag}_{5} \mathrm{Ni}_{5}$ and $\mathrm{Ag}_{6} \mathrm{Ni}_{6}$ for the lowest-energy isomers (top) and isomers of Fig. 5 (bottom). Structures, relative energies, spin multiplicities, and spatial symmetries are shown. 

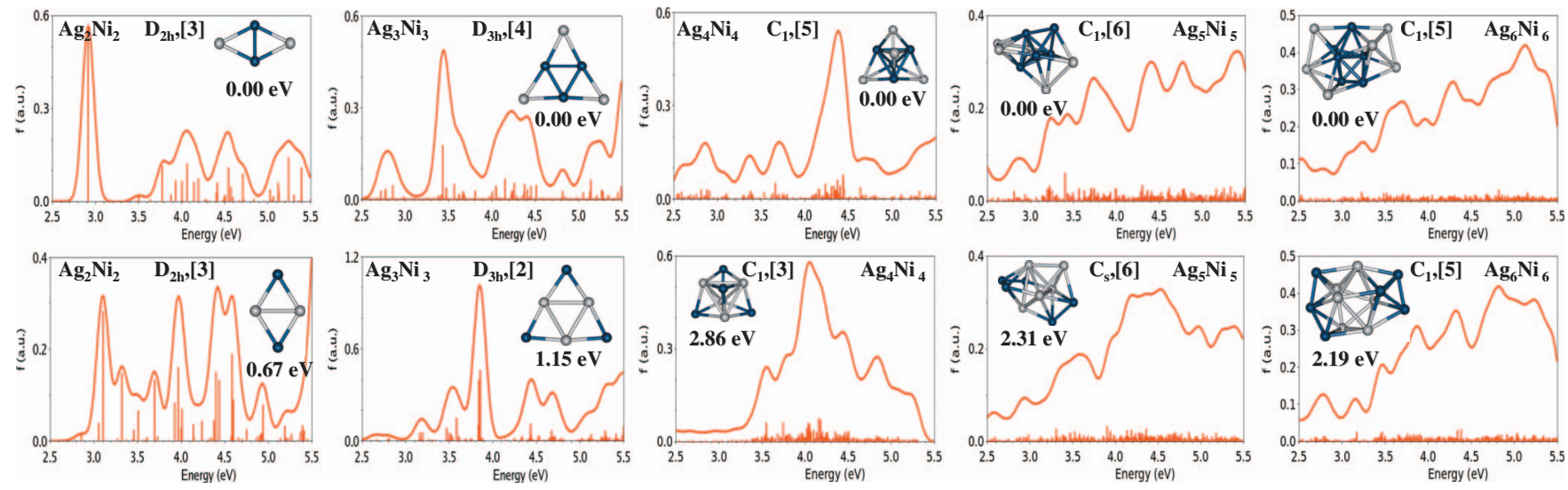

FIG. 7. Absorption spectra of Ni-core/Ag-shell and Ag-core/Ni-shell clusters. Spatial symmetries and relative energies are also given.

blueshift of the surface plasmon resonance band with increasing nickel proportion compared to the pure silver cluster. Our study on small particles leads to similar conclusions since the spectra of $\mathrm{Ag}_{n} \mathrm{Ni}_{n}$ bimetallic clusters are found to be blueshifted, broadened, and damped in comparison to those of pure $\mathrm{Ag}_{n}$, with a strong dispersion of the oscillator strengths on all the range of energy without any dominant peak.

\section{Ni-core/Ag-shell versus Ag-core/Ni-shell}

Figure 7 gives the absorption spectra for both core/shell structures: Ni-core/Ag-shell (already discussed above) and Ag-core/Ni-shell structures obtained after permutations of nickel and silver atoms. After local optimizations, the Ag-core/Ni-shell structures are found to be stable from 0.67 to $2.86 \mathrm{eV}$ above the $\mathrm{Ni}$-core/Ag-shell structures (see the exact relative energies in Fig. 7). The description of the present structures as core/shell structures could appear to be excessive since the number of shell atoms is not enough to form a complete shell, but we will use this label in the discussion for clearness. Figure 7 shows that the optical responses are clearly dependent on the type of the core/shell structure for $n \leq 4$. For $\mathrm{Ag}_{3} \mathrm{Ni}_{3}$, the spectrum of the $\mathrm{Ag}_{3}$-core/ $\mathrm{Ni}_{3}$-shell structure is very different from that of $\mathrm{Ni}_{3}$-core $/ \mathrm{Ag}_{3}$-shell structure, the main bands being blueshifted by about $0.4 \mathrm{eV}$. For $n=4$, while the spectrum of the $\mathrm{Ni}_{4}$-core $/ \mathrm{Ag}_{4}$-shell structure is composed of several minor bands between 2.5 and $3.8 \mathrm{eV}$ followed by a main peak at $4.4 \mathrm{eV}$, that of the $\mathrm{Ag}_{4}$-core $/ \mathrm{Ni}_{4}$-shell structure shows a very broad band between 3.4 and $5.3 \mathrm{eV}$, centered at $4.0 \mathrm{eV}$, without any significant transitions before $3.3 \mathrm{eV}$. In contrast, for $n \geq 5$, the spectra of both types of core/shell structures are very similar, with a strong dispersion of the oscillator strengths on all the range of energy without any dominant peak, even if the response is stronger for states in the high energy region. These spectra are very similar to those of pure nickel clusters shown in Fig. 5, which leads to guess an important role of the electrons of nickel atoms in the excitations.

In a previous work on small $\operatorname{Ag}_{n} \mathrm{Ni}_{n}(n \leq 3)$ clusters, ${ }^{35}$ we have shown that the absorption spectra are very dependent of the Ni-Ni bonds in the cluster. In particular, an analysis of the electronic transitions based on the plots of isosur- faces of the difference between the electron density of the excited state and of the ground state has shown a change in the shape of spectra with the formation of a $\mathrm{Ni}_{3}$ core in the cluster. Indeed, clusters with very few nickel atoms and without connection between nickel atoms give transitions associated to excitations essentially from $s$-type orbitals of silver to $s+p$ orbitals, with very few contributions of $d$-electrons of silver and nickel atoms. Besides, the electron transfer associated to the transitions was found to be localized on each atom (i.e., each atom presents both a positive and negative area). In contrast, when a $\mathrm{Ni}_{3}$ core appears in the cluster, the electron transfer was clearly seen from the $\mathrm{Ni}_{3}$-core to an outer area surrounding the cluster, the $d$ electrons of nickel being now active in the transitions. In the present work, the crucial role of $\mathrm{Ni}-\mathrm{Ni}$ bonds on the absorption spectra also appears. For $n \leq 4$, the differences between spectra of Ag-core/Ni-shell and Ni-core/Ag-shell structures are due to the difference in neighboring of nickel atoms, either surrounded by silver atoms or by nickel ones. In contrast, for $n \geq 5$, both core/shell structures give similar spectra to those of $\mathrm{Ni}_{2 n}$ since the presence of an important number of $\mathrm{Ni}$ atoms leads to several $\mathrm{Ni}-\mathrm{Ni}$ bonds and the formation of a $\mathrm{Ni}_{3}$ core in each structure. The great similarity of the spectra compared to those of $\mathrm{Ni}_{2 n}$ indicates that the $d$-electrons of Ni should play an important role in the excitations. However it remains difficult to perform a precise analysis of the electronic excitations because in these relatively large bimetallic clusters, the excited states lead to a quasicontinuum spectrum. Besides, each peak involves several molecular excitations with equivalent weights. An analysis based on the orbitals is then not relevant. Following this, we have chosen to characterize the electronic excitations by the electron density difference between the excited and ground states for some peaks. We present results for the higher-intensity peaks; as they are part of a continuum we have checked that the conclusions found for these peaks are generalized for the others. In Fig. 8, light (red online) regions correspond to the depletion of the electron density during the transition while the dark (blue online) regions correspond to an increase in the electron density. For pure $\mathrm{Ni}_{10}$ cluster, the transitions are due to the excitations from inner $d$-orbitals to the outer region with an $s+p$ character distributed on the whole cluster. For $\mathrm{Ag}_{5} \mathrm{Ni}_{5}$ clusters, the excitations are from $d$-orbitals of nickel 


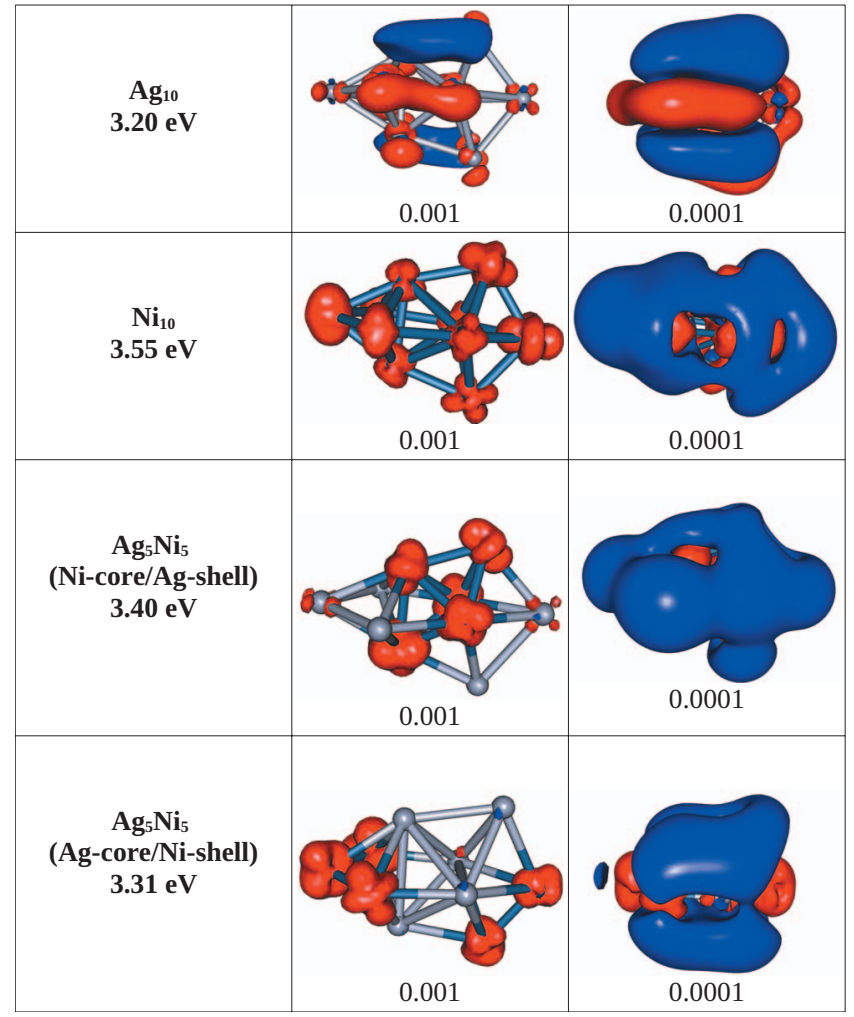

FIG. 8. Isosurface of the electron density difference between the excited and ground states for the some peaks of $\mathrm{Ag}_{10}, \mathrm{Ag}_{5} \mathrm{Ni}_{5}$, and $\mathrm{Ni}_{10}$ clusters. The isovalues are given in a.u. Light regions (red online) correspond to the depletion of the electron density during the transition while the dark (blue online) regions correspond to the accumulation of electrons.

atoms with a very weak contribution from silver atoms to wide areas involving all atoms. This is the case as well for $\mathrm{Ni}$-core/Ag-shell as for Ag-core/Ni-shell structures. Hence, the great similarity of the absorption spectra with that of $\mathrm{Ni}_{2 n}$ is explained by the similarities in the electronic transitions. In contrast, the transitions in $\mathrm{Ag}_{10}$ are more local with alternated positive and negative contributions.

\section{CONCLUSION}

The structural, electronic, and optical properties of bimetallic $\mathrm{Ag}_{n} \mathrm{Ni}_{n}(n \leq 7)$ clusters in gas phase have been carried out in the framework of the DFT (DFT and TDDFT). The structures of $\mathrm{Ag}_{n} \mathrm{Ni}_{n}$ clusters are found to be governed by the formation of a Ni-core surrounded by silver atoms, in good adequacy with recent low energy ion spectroscopy measurements, ${ }^{17}$ which has shown that the cluster surface is essentially composed of silver atoms. The UV-visible absorption spectra of small bimetallic clusters are found to be similar to those of pure $\mathrm{Ag}_{2 n}$ clusters with a dominant peak around $3 \mathrm{eV}$ while those of larger clusters $(n \geq 5)$ are similar to those of pure $\mathrm{Ni}_{2 n}$ with a very broad band. The shape of the spectra is very dependent on the $\mathrm{Ni}-\mathrm{Ni}$ bonds in the cluster. An analysis of the electronic excitations has shown the crucial role of the $d$ electrons of nickel atoms in the optical transitions in Ni-rich systems.

\section{ACKNOWLEDGMENTS}

The authors thank the Pôle Scientifique de Modélisation Numérique (PSMN) at Lyon, France, for generous allocation of computation time.

${ }^{1}$ P. A. Derosa, J. M. Seminario, and P. B. Balbuena, J. Phys. Chem. A 105, 7917 (2001)

${ }^{2}$ V. Bonačić-Koutecký, J. Burda, R. Mitrić, M. Ge, G. Zampella, and P. Fantucci, J. Chem. Phys. 117, 3120 (2002).

${ }^{3}$ H. M. Lee, M. Ge, B. R. Sahu, P. Tarakesshwar, and K. S. Kim, J. Phys. Chem. B 107, 9994 (2003).

${ }^{4}$ G. Rossi, A. Rapallo, C. Mottet, A. Fortunelli, F. Baletto, and R. Ferrando, Phys. Rev. Lett. 93, 105503 (2004).

${ }^{5}$ F. Baletto, C. Mottet, A. Rapallo, G. Rossi, and R. Ferrando, Surf. Sci. 566, 192-196 (2004)

${ }^{6}$ G. Rossi, R. Ferrando, A. Rapallo, A. Fortunelli, B. C. Curley, L. D. Lloyd, and R. L. Johnston, J. Chem. Phys. 122, 194309 (2005).

${ }^{7}$ A. Rapallo, G. Rossi, R. Ferrando, A. Fortunelli, B. C. Curley, L. D. Lloyd, G. M. Tarbuck, and R. L. Johnson, J. Chem. Phys. 122, 194308 (2005).

${ }^{8}$ R. Ferrando, A. Fortunelli, and G. Rossi, Phys. Rev. B 72, 085449 (2005).

${ }^{9}$ X.-J. Hou, E. Janssens, P. Lievens, and M. T. Nguyen, Chem. Phys. 330, 365 (2006).

${ }^{10}$ E. Janssens, S. Neukemans, M. T. Nguyen, and P. Lievens, J. Chem. Phys. 124, 184319 (2006).

${ }^{11}$ G. F. Zhao and Z. Zeng, J. Chem. Phys. 125, 014303 (2006).

${ }^{12}$ R. Ferrando, A. Fortunelli, and R. L. Johnston, Phys. Chem. Chem. Phys. 10, 640 (2008).

${ }^{13}$ E. Cottancin, J. Lermé, M. Gaudry, M. Pellarin, J.-L. Vialle, and M. Broyer, Phys. Rev. B 62, 5179 (2000).

${ }^{14}$ M. Gaudry, J. Lermé, E. Cottancin, M. Pellarin, J.-L. Vialle, M. Broyer, B. Prével, M. Treilleux, and P. Mélinon, Phys. Rev. B 64, 085407 (2001).

${ }^{15}$ H. Portales, L. Saviot, E. Duval, M. Gaudry, E. Cottancin, M. Pellarin, J. Lermé, and M. Broyer, Phys. Rev. B 65, 165422 (2002).

${ }^{16}$ M. Moskovits, I. Srnova-Sloufova, and B. Vickova, J. Chem. Phys. 116, 10435 (2002).

${ }^{17}$ M. Gaudry, E. Cottancin, M. Pellarin, J. Lermé, L. Arnaud, J. R. Huntzinger, J. L. Vialle, and M. Broyer, Phys. Rev. B 67, 155409 (2003).

${ }^{18}$ S. Sun, C. B. Murray, D. Weller, L. Folks, and A. Moser, Science 287, 1989 (2000).

${ }^{19}$ S. Dennler, J. L. Ricardo-Chavez, J. Morillo, and G. M. Pastor, Eur. Phys. J. D 24, 237 (2003).

${ }^{20}$ E. Janssens, S. Neukermans, H. M. T. Nguyen, M. T. Nguyen, and P. Lievens, Phys. Rev. Lett. 94, 113401 (2005).

${ }^{21}$ A. M. Molenbroek, J. K. Norskov, and B. S. Clausen, J. Phys. Chem. B 105, 5450 (2001).

${ }^{22}$ R. Mitric, C. Burgel, J. Burda, V. Bonacic-Koutecky, and P. Fantucci, Eur. Phys. J. D 24, 41 (2003).

${ }^{23}$ J. J. Zhao and R. H. Xie, Phys. Rev. B 68, 035401 (2003).

${ }^{24}$ Z. Zhang, T. M. Nemoff, J. Y. Huang, D. T. Berry, and P. P. Provencio, J. Phys. Chem. C 113, 1155 (2009).

${ }^{25}$ F. Calvo, E. Cottancin, and M. Broyer, Phys. Rev. B 77, 121406(R) (2008).

${ }^{26}$ T. B. Massalski, J. L. Murray, L. H. Bernett, and H. Baker, Binary Alloy Phase Diagrams (American Society for Metals, Metals Park, OH, 1986), Vol. 1.

${ }^{27}$ M. Harb, F. Rabilloud, and D. Simon, J. Phys. Chem. A 111, 7726 (2007).

${ }^{28}$ L. Tiggesbaumker, L. Koller, H. O. Lutz, and K. H. Meiwes-Broer, Chem. Phys. Lett. 190, 42 (1992).

${ }^{29}$ S. Fedrigo, W. Harbich, and J. Buttet, Phys. Rev. B 47, 10706 (1993).

${ }^{30}$ K. Yabana and G. F. Bertsch, Phys. Rev. A 60, 3809 (1999).

${ }^{31}$ V. Bonačić-Koutecký, V. Veyret, and R. Mitric, J. Chem. Phys. 115, 10450 (2001).

${ }^{32}$ G. F. Zhao, Y. Lei, and Z. Zeng, Chem. Phys. 327, 261 (2006).

${ }^{33}$ K. Baishya, J. C. Idrobo, S. Ogut, M. Yang, K. Jackson, and J. Jellinek, Phys. Rev. B 78, 075439 (2008).

${ }^{34}$ M. Harb, F. Rabilloud, D. Simon, A. Rydlo, S. Lecoultre, F. Conus, V. Rodrigues, and C. Félix, J. Chem. Phys. 129, 194108 (2008).

${ }^{35}$ M. Harb, F. Rabilloud, and D. Simon, Chem. Phys. Lett. 449, 38 (2007).

${ }^{36}$ M. F. Frisch, G. W. Trucks, H. B. Schlegel et al., GAUsSIAN 03, revision D.01, Gaussian, Inc., Wallingford, CT, 2004. 
${ }^{37}$ A. D. Becke, Phys. Rev. A 38, 3098 (1988).

${ }^{38}$ J. P. Perdew, Phys. Rev. B 33, 8822 (1986).

${ }^{39}$ F. Rabilloud, F. Spiegelman, J. M. L'Hermite, and P. Labastie, J. Chem. Phys. 114, 289 (2001).

${ }^{40}$ M. N. Huda and A. K. Ray, Eur. Phys. J. D 22, 217 (2003).

${ }^{41}$ M. Harb, F. Rabilloud, and D. Simon, Chem. Phys. Lett. 476, 186 (2009).

${ }^{42}$ P. J. Hay and W. R. Wadt, J. Chem. Phys. 82, 299 (1985).

${ }^{43}$ S. K. Nayak, S. N. Khanna, B. K. Rao, and P. Jena, J. Phys. Chem. A 101, 1072 (1997).

${ }^{44}$ G. Lopez Arvizu and P. Calaminici, J. Chem. Phys. 126, 194102 (2007).

${ }^{45}$ Y. Shao, L. F. Molnar, Y. Jung, J. Kussmann, C. Ochsenfeld, S. T. Brown, A. T. B. Gilbert, L. V. Slipchenko, S. V. Levchenko, D. P. O'Neill, R. A. DiStasio, Jr., R. C. Lochan, T. Wang, G. J. O. Beran, N. A. Besley, J. M. Herbert, C. Y. Lin, T. Van Voorhis, S. H. Chien, A. Sodt, R. P. Steele, V. A. Rassolov, P. E. Maslen, P. P. Korambath, R. D. Adamson, B. Austin, J. Baker, E. F. C. Byrd, H. Dachsel, R. J. Doerksen, A. Dreuw, B. D Dunietz, A. D. Dutoi, T. R. Furlani, S. R. Gwaltney, A. Heyden, S. Hirata, C.-P. Hsu, G. Kedziora, R. Z. Khalliulin, P. Klunzinger, A. M. Lee, M. S. Lee, W. Liang, I. Lotan, N. Nair, B. Peters, E. I.
Proynov, P. A. Pieniazek, Y. M. Rhee, J. Ritchie, E. Rosta, C. D. Sherrill, A. C. Simmonett, J. E. Subotnik, H. Lee Woodcock III, W. Zhang, A. T. Bell, A. K. Chakraborty, D. M. Chipman, F. J. Keil, A. Warshel, W. J. Hehre, H. F. Schaefer III, J. Kong, A. I. Kryolov, P. M. W. Gill, and M. Head-Gordon, Phys. Chem. Chem. Phys. 8, 3172 (2006).

${ }^{46} \mathrm{~A}$. R. Allouche, GABEDIT is a free graphical user interface for computational chemistry packages. It is available from http://gabedit.sourceforge.net.

${ }^{47}$ C. Jackschath, I. Rabin, and W. Schulze, Z. Phys D: At., Mol. Clusters 22, 517 (1992).

${ }^{48}$ C. M. Aikens and G. C. Schatz, J. Phys. Chem. A 110, 13317 (2006).

${ }^{49}$ M. R. Silva-Junior, M. Schreiber, S. P. Sauer, and W. Thiel, J. Chem. Phys. 129, 104103 (2008).

${ }^{50}$ D. Jacquemin, V. Wathelet, E. A. Perpète, and C. Adamo, J. Chem. Theory Comput. 5, 2420 (2009).

${ }^{51}$ J. P. Perdew, K. Burke, and M. Ernzerhof, Phys. Rev. Lett. 77, 3865 (1996).

${ }^{52}$ C. Lee, W. Yang, and R. G. Parr, Phys. Rev. B 37, 785 (1988).

${ }^{53}$ A. D. Becke, J. Chem. Phys. 98, 5648 (1993). 